J. Dairy Sci. 95:4733-4733

http://dx.doi.org/10.3168/jds.2012-95-8-4733

(C) American Dairy Science Association ${ }^{\circledR}, 2012$.

\title{
Erratum to "Ruminal escape and intestinal digestibility of ruminally protected lysine supplements differing in oleic acid and lysine concentrations” (J. Dairy Sci. 95:2680-2684)
}

Z. Wu, J. K. Bernard, R. B. Eggleston, and T. C. Jenkins

In Table 2 (page 2682), the units for the last 2 rows should be grams (g), not percentage (\%). The corrected table is shown below.

The authors regret the error.

Table 2. Ruminal escape ${ }^{1}$ and intestinal digestibility of experimental protected Lys supplements containing 55 or $58 \%$ lysine sulfate with 2 or $4 \%$ oleic acid in the coating

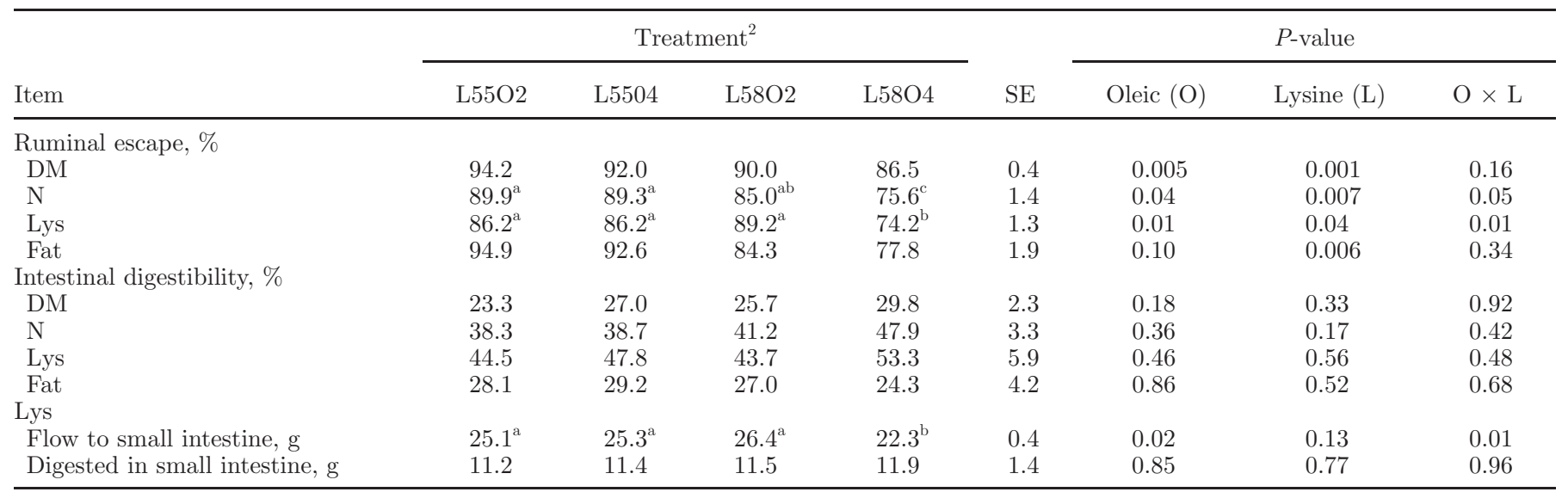

${ }^{\mathrm{a}-\mathrm{c}}$ Means within a row with different superscripts differ $(P<0.05)$.

${ }^{1}$ Measured after 16-h incubation in the rumen.

${ }^{2} \mathrm{~L} 55 \mathrm{O} 2=55 \%$ lysine sulfate and $2 \%$ oleic acid; L55O4 = 55\% lysine sulfate and $4 \%$ oleic acid; L58O2 = 58\% lysine sulfate and $2 \%$ oleic acid; and $\mathrm{L} 58 \mathrm{O} 4=58 \%$ lysine sulfate and $4 \%$ oleic acid.

\section{REFERENCES}

Wu, Z., J. K. Bernard, R. B. Eggleston, and T. C. Jenkins. 2012. Ruminal escape and intestinal digestibility of ruminally protected lysine supplements differing in oleic acid and lysine concentrations. J. Dairy Sci. 95(5):2680-2684. 